\title{
Association of metabolically healthy obesity and elevated risk of coronary artery calcification: A systematic review and meta-analysis
}

\author{
Yu-wen Hsueh ${ }^{\text {Equal first author, } 1}{ }^{\text {, Tzu-Lin Yeh }}{ }^{2,3}{ }$, Chien-Yu Lin ${ }^{4}$, Szu-Ying Tsai ${ }^{5}$, Shu-Jung Liu ${ }^{6}$, Chi-Min Lin ${ }^{2}$, Hsinhao

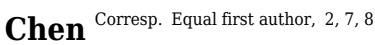

Background: Metabolically healthy obesity (MHO) is defined as obesity with less than 2 parameters of metabolic abnormalities. Some studies report that MHO individuals show similar risk of cardiovascular disease(CVD) compared with metabolically healthy non-obese(MHNO) individuals, but the results are conflicting. Coronary artery calcium (CAC) reflects the extent of coronary atherosclerosis and is a useful tool to predict future risk of CVD. The objective of this meta-analysis was to investigate whether $\mathrm{MHO}$ is associated with elevated risk of CAC.

Method: We searched Cochrane, PubMed, and Embase up to April 19, 2019. Prospective cohort and cross-sectional studies examining the association between MHO subjects and CAC were included with MHNO as the reference. Pooled odds ratio (OR) and 95\% confidence interval $(\mathrm{Cl})$ were calculated using random-effect models. Subgroup analysis and meta-regression were applied to define possible sources of heterogeneity. We conducted this research following a pre-established protocol registered on PROSPERO (CRD 42019135006).

Results: A total of nine studies were included in this review and six studies with 23,543 participants were eligible for the meta-analysis. Compared with MHNO subjects, MHO had a higher odds of CAC (OR $1.36,95 \% \mathrm{Cl}$ [1.11 to 1.66 ]; $I^{2}=39 \%$ ). In the subgroup analysis, the risk associated with MHO participants was significant in cohort studies (OR $\left.=1.47,95 \% \mathrm{Cl}[1.15,1.87], I^{2}=0 \%\right)$, and borderline significant in cross-sectional studies. The risk of CAC was also significant in MHO participants defined by Adult Treatment Panel III (ATP III) (OR =1.55, 95\% Cl [1.25,1.93], $\left.I^{2}=0 \%\right)$. The univariate meta-regression model showed that age and smoking status were possible effect modifiers for MHO and CAC risk.

Conclusion: Our meta-analysis showed that MHO phenotypes were associated with elevated risk of CAC compared with MHNO, which reflects the extent of coronary atherosclerosis. People with obesity should strive to achieve normal weight even when only one metabolic abnormality is present. 
1 Association of Metabolically Healthy Obesity and Elevated Risk of Coronary Artery

2 Calcification: A Systematic Review and Meta-analysis

3 Yu-wen Hsueh ${ }^{1}$, Tzu-Lin Yeh ${ }^{2,3}$, Chien-Yu Lin ${ }^{4}$, Szu-Ying Tsai ${ }^{5}$, Shu-Jung Liu ${ }^{6}$, Chi-Min Lin ${ }^{2}$,

4 Hsin-Hao Chen ${ }^{2,7,8}$

$5 \quad{ }^{1}$ Department of Internal Medicine, MacKay Memorial Hospital, Taipei, Taiwan

$6{ }^{2}$ Department of Family Medicine, Hsinchu MacKay Memorial Hospital, Hsinchu City, Taiwan

7 Institute of Epidemiology and Preventive Medicine, National Taiwan University, Taipei,

8 Taiwan

$9{ }^{4}$ Department of Pediatrics, Hsinchu MacKay Memorial Hospital, Hsinchu, Taiwan

$10{ }^{5}$ Department of Family Medicine, MacKay Memorial Hospital, Taipei, Taiwan

$11{ }^{6}$ Department of Medical Library, MacKay Memorial Hospital, Tamsui Branch, New Taipei City,

12 Taiwan

$13{ }^{7}$ MacKay Junior College of Medicine, Nursing, and Management, Taipei City, Taiwan

$14{ }^{8}$ Department of Medicine, MacKay Medical College, No.46, Sec. 3, Zhongzheng Rd.,

15 Sanzhi Dist., New Taipei City, Taiwan

16 Corresponding author: Dr. Hsin-Hao, Chen

17 Address: No. 690, Section 2, Guangfu Road, East District, Hsinchu City, Taiwan

18 Tel: +886-3-6889595

19 Fax: +886-3-6110900 
20 Email: 2033@mmh.org.tw 


\section{Abstract}

23 Background: Metabolically healthy obesity (MHO) is defined as obesity with less than 2

24 parameters of metabolic abnormalities. Some studies report that MHO individuals show similar

25 risk of cardiovascular disease (CVD) compared with metabolically healthy non-obese (MHNO)

26 individuals, but the results are conflicting. Coronary artery calcium (CAC) reflects the extent of

27 coronary atherosclerosis and is a useful tool to predict future risk of CVD. The objective of this

28 meta-analysis was to investigate whether MHO is associated with elevated risk of CAC.

29 Method: We searched Cochrane, PubMed, and Embase up to April 19, 2019. Prospective cohort

30 and cross-sectional studies examining the association between MHO subjects and CAC were

31 included with MHNO as the reference. Pooled odds ratio (OR) and 95\% confidence interval (CI)

32 were calculated using random-effect models. Subgroup analysis and meta-regression were

33 applied to define possible sources of heterogeneity. We conducted this research following a pre-

34 established protocol registered on PROSPERO (CRD 42019135006).

35 Results: A total of nine studies were included in this review and six studies with 23,543

36 participants were eligible for the meta-analysis. Compared with MHNO subjects, MHO had a

37 higher odds of CAC (OR 1.36, 95\% CI [1.11 to 1.66$] ; I^{2}=39 \%$ ). In the subgroup analysis, the risk

38 associated with $\mathrm{MHO}$ participants was significant in cohort studies $(\mathrm{OR}=1.47,95 \% \mathrm{CI}$

$39[1.15,1.87], I^{2}=0 \%$, and borderline significant in cross-sectional studies. The risk of CAC was 
40 also significant in MHO participants defined by Adult Treatment Panel III (ATP III) (OR $=1.55$,

$\left.4195 \% \mathrm{CI}[1.25,1.93], I^{2}=0 \%\right)$. The univariate meta-regression model showed that age and smoking

42 status were possible effect modifiers for $\mathrm{MHO}$ and CAC risk.

43 Conclusion: Our meta-analysis showed that MHO phenotypes were associated with elevated

44 risk of CAC compared with MHNO, which reflects the extent of coronary atherosclerosis.

45 People with obesity should strive to achieve normal weight even when only one metabolic

46 abnormality is present.

47 Key words: metabolically healthy obesity, coronary artery calcification, meta-analysis 
49

50

51 third of the global population is overweight or obese.(Collaboration 2016) Obesity is associated

5 with a higher risk of incident metabolic syndrome, which in turn is associated with a two-fold increase in the risk of CVD and a 1.5-fold increase in the risk of all-cause mortality.(Bastien et al. 2014; Mongraw-Chaffin et al. 2016; Mottillo et al. 2010) Therefore, it has become a major global health burden.(Seidell \& Halberstadt 2015) However, not all obese individuals have metabolic abnormalities. This group includes those without insulin resistance, dyslipidemia, glucose intolerance, hypertension, or high inflammatory

58 59 status.(Velho et al. 2010) Recent research has focused on a phenotype of obese individuals, termed the MHO, referring to obese subjects with less than 2 risk parameters of the metabolic syndrome (except accounting for waist circumference) and elevated homeostatic model for assessing insulin resistance (HOMA-IR) and elevated c-reactive protein (CRP) levels, which is now being widely used. (Stefan et al. 2017) Based on different criteria of metabolic syndrome as well as sex and age, MHO accounts for as much as $30 \%-40 \%$ of the obese adult population.(Stefan et al. 2013; Velho et al. 2010; Wildman et al. 2008; Zheng et al. 2016) Earlier epidemiological studies indicate that MHO individuals are not at increased risk of CVD after a short term follow-up.(Appleton et al. 2013; Hamer \& Stamatakis 2012; Hosseinpanah et al. 
67 2011) However, the link between MHO and CVD remains controversial. Some meta-analyses

68 have reported that obese individuals with metabolic phenotypes considered 'healthy' are still at

69 increased risk of CVD after sufficient long-term follow up.(Kramer et al. 2013; Mirzababaei et

70 al. 2019) On the other hand, no uniform definition of MHO was established during these studies.

71 Most studies defined $\mathrm{MHO}$ as a combination of four common metabolic criteria: blood pressure,

72 high-density lipoprotein cholesterol (HDL-C), triglycerides (TG), and fasting plasma glucose.

73 Other components, such as HOMA-IR or CRP, were not readily adopted.(Roberson et al. 2014)

74 One meta-analysis in 2015 also indicated that stricter criteria may be needed to identify benign

75 obesity phenotypes.(Eckel et al. 2016)

76 Coronary artery calcium (CAC), detected by coronary multidetector computed tomography

77 (MDCT), reflects the extent of subclinical atherosclerosis and suggests the presence of

78 CVD.(Budoff et al. 2006) Previous studies that examined the link between MHO and CAC found

79 inconsistent results and several limitations existed with regards to the association of MHO and

80 CAC progression.(Chang et al. 2014; Echouffo-Tcheugui et al. 2019; Kang et al. 2017; Rhee et

81 al. 2013; Yoon et al. 2017) Some of them were cross-sectional studies, conducted in Asian

82 populations, which did not allow us to examine the temporal relationship between $\mathrm{MHO}$ and

83 CAC progression.(Chang et al. 2014; Jung et al. 2014; Rhee et al. 2013; Sung et al. 2014)

84 Absence of a common definition for MHO made it difficult to clarify whether the MHO 
85 phenotype is harmful to coronary arteries. Since CAC is an important indicator of atherosclerotic

86 disease, defining the extent of calcification in coronary arteries, the objective of this study was to

87 systematically and comprehensively explore the relationship between MHO and CAC risk in

88 comparison to MHNO participants.

89 
90

91

92

Preferred Reporting Items for Systematic Reviews and Meta-analyses (PRISMA)

94 guidelines.(Shamseer et al. 2015) (Table. S1) All authors declare that there is no conflict of

95 96 and any disagreements were resolved via discussion with a third author, Chien-Yu Lin. We also

\section{Methods}

protocol registered on PROSPERO (CRD 42019135006) and reported in accordance with the

This systematic review and meta-analysis were conducted following a pre-established

interest regarding the publication of this study. The research did not receive any specific grants

from funding agencies in the public, commercial or not-for-profit sectors.

Data sources and searches

We performed a systematic literature search using the Medline, EMBASE, and Cochrane

library databases supplemented with the manual review of the reference list of obtained articles

up to April 19, 2019. We used different combinations of the following Medical Subject Headings

(MeSH) terms: ["coronary calcification" or "coronary calcium" or "coronary atherosclerosis" or

"vascular calcification"] and [ "Metabolically Benign Obesity", "Metabolically Healthy

Obesity", "obesity phenotype"]. Full search strategies are shown in Table. S2. Articles were

selected if the title or abstract indicated that the study analyzed the association between CAC and MHO. Two authors, Hsin-Hao Chen and Yu-Wen Hsueh, independently conducted the searches

performed a manual search of references from relevant publications, as well as previous reviews 
108 and meta-analyses. Parameter ranges for language, year of publication, article type, and

109 participant characteristics including age were not limited to enable a relatively comprehensive

110 search.

111 Study selection

112 We included all eligible publications that satified our inclusion criteria: (1) published

113 observational cohort and cross-sectional studies investigating MHO and CAC conducted on

114 adults; (2) classification of obesity and non-obesity by waist circumference (WC) in addition to

115 the body mass index (BMI) shown in the pre-established protocol; (3) reporting of criteria used

116 to define metabolically healthy/unhealthy (MH/MUH) phenotypes; (4) presence of a reference

117 group with metabolically healthy non-obese or normal weight individuals; (5) reporting of the

118 presence, extent, new development, or progression of CAC, assessed by electron beam computed

119 tomography (EBCT) or MDCT. Studies were excluded if they (1) were duplicate publications,

120 (2) topically irrelevant, (3) did not compare MHO and CAC with MHNO or metabolically

121 healthy normal weight (MHNW) people, or (4) were literature reviews, republished data, case

122 reports, dissertations, or conference abstracts.

123 Data extraction and quality assessment

124 We extracted the following information: first author's name, year of publication, description

125 of the study population (country, number of participants/cases per MHO phenotype, mean age, 
126 sex proportion, duration of follow-up in cohort studies), study design, definition of metabolically

127 healthy and obese, diagnostic methods of CAC, adjusted variables, and main outcome presented

128 with OR (95\%CI) using $\mathrm{MHNO}$ as the reference.

129 The quality of the included studies was assessed independently by two authors, Chien-Yu

130 Lin and Szu-Ying Tsai, using the Newcastle Ottawa Scale (NOS). The quality assessment tool

131 rates each study in three domains — selection, comparability, and outcome —using a star system

132 ranging from zero to nine stars in cohort studies and from zero to ten stars in cross-sectional

133 studies. (Zeng et al. 2015) If two authors disagree, the decision was made by the third author,

134 Chi-Min Lin. A study was considered to be of high quality if the cohort study obtained at least

135 six stars and the cross-sectional study obtained at least seven stars.

136 Statistical analysis and Data synthesis

137 We calculated pooled odds ratios (ORs) with $95 \%$ CIs for estimating the risk of CAC

138 progression in MHO compared with MHNO. We used statistical computing software R, Version

139 1.1.456, primarily using the Comprehensive R Archive Network (CRAN) package "metagen"for

140 our meta-analysis.(Team 2013) We employed a random effects model using DerSimonian and

141 Laird's method under an assumption of non-identical true effect sizes.(DerSimonian \& Laird

142 1986) The results were presented as forest plots. Heterogeneity among studies was quantified by

143 Cochran's Q test and $I^{2}$ statistics (Higgins \& Thompson 2002) and further explored by pre- 
144 specified subgroup analyses. We also used meta-regression models to test contributions of effect

145 modifiers, consisting of age, sex, and smoking status. (Rothman 2012). With regards to the

146 statistical significance interpretation, we do not treat p-values dichotomously according to the

147 previous studies. We consider the p-values as graded measures of the strength of evidence.

148 (Amrhein et al. 2019; Amrhein et al. 2017) We performed a sensitivity analysis by excluding one

149 study at a time to measure its impact on the robustness of the results. Publication bias was

150 evaluated by funnel plots and Egger's tests with a significant publication bias defined by a $p$

151 value <0.1.(Egger et al. 1997)

152 


\section{Results}

154 Description of studies and quality assessment.

155 The flowchart of article selection is shown in Figure 1. A total of 9 observational studies

156 including cohort(Kang et al. 2017; Kowall et al. 2019; Yoon et al. 2017) and cross-

157 sectional(Chang et al. 2014; Echouffo-Tcheugui et al. 2019; Jung et al. 2014; Khan et al. 2011;

158 Rhee et al. 2013; Sung et al. 2014) studies were included in our systematic review. One article

159 that combined $\mathrm{MHO}$ and metabolically healthy overweight (MHOW) people into one group was

160 excluded from our meta-analysis because it did not comply with our criteria.(Khan et al. 2011)

161 Another two articles were excluded because they were series from the same institutions with

162 possible duplicate participants.(Chang et al. 2014; Rhee et al. 2013) Finally, six studies fulfilled

163 all the inclusion criteria for the meta-analysis.(Echouffo-Tcheugui et al. 2019; Jung et al. 2014;

164 Kang et al. 2017; Kowall et al. 2019; Sung et al. 2014; Yoon et al. 2017)

165 The general demographic characteristics of subjects in the nine included studies in the

166 systematic review are summarized in Table 1. Among the 62,909 participants, $16.8 \%$ were

$167 \mathrm{MHO}$, with a mean age of 42.2 years and a $46.6 \%$ female proportion. All included studies were

168 published after 2011 and most were conducted in Korea,(Chang et al. 2014; Jung et al. 2014;

169 Kang et al. 2017; Rhee et al. 2013; Sung et al. 2014; Yoon et al. 2017) followed by the USA

170 (Echouffo-Tcheugui et al. 2019; Khan et al. 2011) and Germany.(Kowall et al. 2019) One study 
171 was restricted to women.(Khan et al. 2011) Sample size varied substantially among studies,

172 ranging from 475 to 24,063 participants. The duration of follow-up ranged from 2.9 to 5.1 years

173 in the three cohort studies, (Kang et al. 2017; Kowall et al. 2019; Yoon et al. 2017) while the

174 remaining were cross-sectional studies. (Chang et al. 2014; Echouffo-Tcheugui et al. 2019; Jung

175 et al. 2014; Khan et al. 2011; Rhee et al. 2013; Sung et al. 2014)

176 Obesity was defined by a BMI $\geq 25$ in the Korean studies (Chang et al. 2014; Jung et al.

177 2014; Kang et al. 2017; Rhee et al. 2013; Sung et al. 2014; Yoon et al. 2017) and $\geq 30$ in the

178 German and USA studies.(Echouffo-Tcheugui et al. 2019; Khan et al. 2011; Kowall et al. 2019)

179 Metabolic status was defined by ATP III criteria only in four studies(Echouffo-Tcheugui et al.

180 2019; Kang et al. 2017; Kowall et al. 2019; Yoon et al. 2017) with additional assessment of

181 HOMA-IR or CRP in two studies.(Chang et al. 2014; Khan et al. 2011) The other three studies

182 used Joint Interim Statement (JIS)(Sung et al. 2014) and Wildman criteria.(Jung et al. 2014;

183 Rhee et al. 2013).

184 For evaluating outcomes, the three cohort studies used CAC progression as expressed by a

185 categorical change or change in the absolute coronary artery calcification score (CACS).(Kang et

186 al. 2017; Kowall et al. 2019; Yoon et al. 2017) The other cross-sectional studies used OR at

187 different CACS cut-off points or categories with the MHNO group as the reference. (Chang et al.

188 2014; Echouffo-Tcheugui et al. 2019; Jung et al. 2014; Khan et al. 2011; Rhee et al. 2013; Sung 
189

190

191

192 193

194

195

196

197

198

199

200

201

202

203

204 205

et al. 2014)

assessment scale (shown in Table. S1). The cross-sectional studies scored from seven to nine out of ten stars, indicating that all included studies were of good quality. The detailed scores are shown in Table. S3-1, 3-2.

Results of the meta-analysis

For CAC risk analysis, six observational studies with 23,543 subjects were pooled for the meta-analysis.(Echouffo-Tcheugui et al. 2019; Jung et al. 2014; Kang et al. 2017; Kowall et al. 2019; Sung et al. 2014; Yoon et al. 2017) Participants with MHO had significantly higher odds of CAC than those with $\mathrm{MHNO}\left(\mathrm{OR}=1.36,95 \% \mathrm{CI}[1.11,1.66], I^{2}=39 \%\right.$, Figure 2). Due to the underlying heterogeneity in MHO definitions and article types, we analyzed data in subgroups. Compared with MHNO participants, those with MHO had significantly higher odds of CAC progression in the cohort studies $\left(\mathrm{OR}=1.47,95 \% \mathrm{CI}[1.15,1.87], I^{2}=0 \%\right.$, forest plot shown in Figure 2), and it is very likely that $\mathrm{MHO}$ is associated with CAC prevalence in the cross-sectional studies $\left(\mathrm{OR}=1.31,95 \%\right.$ CI $[0.90,1.91], I^{2}=69 \%$, forest plot shown in Figure 2). Compared with MHNO participants, those with MHO had higher odds of CAC according to metabolic status as defined by the National Cholesterol Education Program-Adult Treatment Panel III (NCEP-ATP III) $\left(\mathrm{OR}=1.55,95 \%\right.$ CI $[1.25,1.93], I^{2}=0 \%$, forest plot shown in Figure 
2073 ), but not according to other definitions ( $\mathrm{OR}=1.15,95 \%$ CI $\left[0.78,1.69, I^{2}=68 \%\right.$, forest plot 208 shown in Figure 3).

209 We also performed meta-regression analyses for potential effect modifiers, consisting of

210 sex, age, and smoking status. Univariate meta-regression showed no statistically significant

211 effect modification with proportion of women $(p=0.31)$ and was borderline significant with age

212 and smoking status ( $p=0.08, p=0.058$; bubble plots shown in Figure. S1-3). When we

213 performed a sensitivity analysis by excluding one article in which the reference group was

214 MHNW (Kowall et al. 2019) rather than non-obese, the result still remained robust $(\mathrm{OR}=1.39$,

$\left.21595 \% \mathrm{CI}[1.10,1.76], I^{2}=50 \%\right)$. We also excluded one study at a time and re-calculated the

216 overall effect estimate, and the results were not changed. No significant publication bias was

217 detected by Egger's tests $(p=0.47)$ and there was no substantial asymmetry in the funnel plot

218 (Figure. S4).

219 


\section{Discussion}

221 The meta-analysis showed that compared to individuals with MHNO, those with MHO

222 phenotypes had a significantly higher odds of CAC, especially in cohort studies and when

223 defined by NCEP-ATP III criteria. Age and smoking status were possible effect modifiers for

$224 \mathrm{MHO}$ and CAC risk.

225 Our study is the first systematic review and meta-analysis to show that MHO phenotype

226 increases the risk of CAC progression, which reflects the extent of coronary atherosclerosis and

227 quite possibly indicates increased future risk of CVD. Some previous studies have reported an

228 association between MHO and CVD risk. One meta-analysis of fourteen prospective studies in

2292013 showed that MHO people had increased risk of CVD with a pooled relative risk (RR) of

$2302.00(95 \%$ CI 1.79-2.24) compared with healthy normal-weight individuals. The results

231 appeared much stronger during the long-term follow-up period of more than 15 years.(Fan et al.

232 2013) Another review in 2013 showed that MHO people are at elevated risk of CVD $(\mathrm{RR}=1.24$,

$23395 \%$ CI [1.02-1.55]) when only studies with 10 or more years of follow-up were considered.

234 (Kramer et al. 2013) Another meta-analysis in 2016 showed that MHO phenotypes defined by

235 different definitions of metabolic syndrome, insulin resistance, or other approaches, were at

236 increased risk for CVD.(Eckel et al. 2016) The significantly higher odds of CAC progression

237 shown in the cohort studies included in our analysis agreed with these previous reviews that 
238 MHO phenotype may not be a benign condition.

239 In the subgroup analysis of our study, MHO participants in cohort studies showed a higher

240 odds of CAC progression, and it is likely that MHO is associated with CAC prevalence in the

241 cross-sectional studies. Of the studies included in our meta-analysis, three were cross-sectional

242 and only offered a snapshot of subclinical coronary atherosclerosis in MHO.(Echouffo-Tcheugui

243 et al. 2019; Jung et al. 2014; Sung et al. 2014) Although two studies still showed higher odds of

244 CAC(Echouffo-Tcheugui et al. 2019; Jung et al. 2014) compared with MHNO subjects, this

245 material did not allow us to examine CAC progression over time. An original pilot study, which

246 invited 88 consecutive community-based participants with a 3.5-year follow-up, indicated a

247 regular CACS increase of 24\% each year since baseline.(Maher et al. 1999) Therefore, given a

248 longer follow-up duration, we were able to detect the significant difference in CAC between

249 MHO and MHNO.

250 Another source of heterogeneity is the definition of metabolic health, regarding which there

251 is still a lack of consensus among MHO-related studies. Most studies included in our meta-

252 analysis (Echouffo-Tcheugui et al. 2019; Kang et al. 2017; Kowall et al. 2019; Yoon et al. 2017)

253 defined metabolic status following NCEP-ATP III, referring to the presence of any three of the

254 following five criteria: (a) serum $\mathrm{TG} \geq 150 \mathrm{mg} / \mathrm{dl}$ or under drug treatment; (b) serum HDL-C $<$

$25540 \mathrm{mg} / \mathrm{dl}$ in men or $<50 \mathrm{mg} / \mathrm{dl}$ in women or under drug treatment; (c) blood pressure of $\geq 130 / 85$ 
$256 \mathrm{mmHg}$ or under drug treatment; (d) fasting plasma glucose $\geq 100 \mathrm{mg} / \mathrm{dL}$ or under drug

257 treatment; and (e) abdominal obesity defined as a $\mathrm{WC}$ of $\geq 102 \mathrm{~cm}$ in men or $\geq 88 \mathrm{~cm}$ in

258 women.(Expert Panel on Detection \& Treatment of High Blood Cholesterol in 2001) All

259 included studies using NCEP-ATP III excluded WC due to collinearity with BMI. The other

260 criteria used to define MHO are the JIS and Wildman criteria. The latest JIS definition is similar

261 to NCEP-ATP III, but with ethnicity-specific WC cut-points.(Alberti et al. 2009) In the Wildman

262 criteria,(Wildman et al. 2008) metabolically healthy is defined as having less than two of the

263 following six risk factors: (a) systolic blood pressure (SBP) $\geq 130 \mathrm{mmHg}$ and/or diastolic blood

264 pressure (DBP) $\geq 85 \mathrm{mmHg}$, or on antihypertensive treatment; (b) $\mathrm{TG} \geq 150 \mathrm{mg} / \mathrm{dl}$ or use of

265 lipid-lowering drugs; (c) fasting glucose $\geq 100 \mathrm{mg} / \mathrm{dl}$ or being treated for diabetes; (d) HDL-C $<$

$26640 \mathrm{mg} / \mathrm{dL}$ in men or $<50 \mathrm{mg} / \mathrm{dL}$ in women; (e) HOMA-IR $>90$ th percentile $(>5.13$ mole $\times$

$\left.267 \mu \mathrm{U} / \mathrm{L}^{2}\right)$; and f) high-sensitivity C-reactive protein (hs-CRP) > 90th percentile $(>0.1 \mathrm{mg} / \mathrm{L})$.

268 Wildman criteria also included HOMA-IR, the core concept of metabolic syndrome, and CRP,

269 the best biomarker of vascular inflammation and predictor of CVD events. (Jeppesen et al. 2008)

270 These criteria modifications for metabolically healthy individuals also explained the

271 heterogeneity in our meta-analysis. Despite the fact that heterogeneity in the subgroup of cohort

272 studies reached zero $\left(I^{2}=0 \%\right)$, the definiton of CAC progression differed in the three included

273 cohort studies. CAC progression was defined by absolute CAC change in two cohort studies 
274 (Kang et al. 2017; Yoon et al. 2017), and a categorical variable for annual CAC change was used

275 in another study(Kowall et al. 2019). So more studies with more uniform standards for CAC

276 evaluation were needed to verify our results.

277 Another issue is that we classified participants as metabolically healthy using at most one

278 component (except WC) from the criteria in our study. However, a previous meta-analysis

279 showed that compared with MHNW, MHO participants not expressing any of these metabolic

280 factors showed no significantly increased CV risk.(Eckel et al. 2016) In one large study by

281 Lassale et al., an increased risk of CHD was found in MHO individuals, when MH was defined

282 by the metabolic syndrome criteria, but not when $\mathrm{MH}$ was defined by the absence of any

283 cardiometabolic risk factor. (Lassale et al. 2017) The conclusion was consistent with the result of

284 our three included studies (Kowall et al. 2019; Sung et al. 2014; Yoon et al. 2017), which

285 showed those without any metabolic risk factor had no significantly higher risk of CAC. This

286 may be one reason for conflicting results in previous studies. Moreover, studies show that CAC

287 risk in $\mathrm{MHO}$ is higher than that in MHNO, but lower than that in metabolically unhealthy obesity

288 (MUO) (Kowall et al. 2019; Sung et al. 2014). This message might be that improving one's

289 metabolic profile may be worthwhile even if the person remains obese. MHO may be an

290 intermediate step for people with MUO to reduce CAC risk. More studies are thus needed to

291 better define metabolically healthy and benign obese phenotypes. 
293 indicated that CAC risk increased with age, whereby the extent of CAC was greater in men

294 compared with women up to the age of 60.(Otsuka et al. 2014) In contrast, smoking was

295 independently related to lipid-rich plaques, contributing to an increased risk of plaque

296 composition.(Kumagai et al. 2015) The CARDIA (Loria et al. 2007) and the Heinz Nixdorf

297 Recall(Lehmann et al. 2014) study show that current smoking was positively associated with

298 CAC risk. This is consistent with our results from the univariate meta-regression, which

299 indicated that impact of MHO on CAC risk decreased as the proportion of smokers increased.

300 Future studies will help confirm that age, sex, and smoking status are potentially very important

301 modifiers of the association effect between $\mathrm{MHO}$ and CAC risk. subjects even without metabolic dysfunction, the adipocyte storage capacity may be exceeded

304 (Bluher 2010) and extra lipid may accumulate ectopically in visceral fat depots, liver, muscle,

305 and $\beta$-cells. These locations are associated with the risk of developing CVD. (Roca-Rivada et al.

306 2015) Inflammation in adipose tissue has been proposed as another key factor, as adipose

307 tissue secretes bioactive peptides, adipokines, interleukin-6, and tumor necrosis factor-alpha,

308 which affect multiple functions, such as immunity, insulin sensitivity, angiogenesis, blood

309 pressure, lipid metabolism, and hemostasis, all of which are linked with CAC.(Ronti et al. 
310 2006) Therefore, obese subjects even without metabolic dysfunction should not be considered as

311 benign phenotypes, but rather as having pre-metabolic syndrome, which is also correlated with a

312 high risk of developing metabolic dysfunction-related cardiovascular comorbidities.(Rasaei et al.

$313 \quad 2018)$

314 Lifestyle intervention is considered safe and effective at decreasing CV risk in obese

315 individuals. (Stefan et al. 2018) In one review of MHO, weight loss of 5-10\% may be enough for

316 better cardiometabolic health, but more weight loss might be needed in higher BMI individuals.

317 (Kantartzis et al. 2011) In addition to weight loss, Mediterranean diet could be combined with

318 weight loss programs for metabolic health. (Estruch et al. 2013) And the absence of fatty liver is

319 also a strong predictor for the regression from metabolically unhealthy to the metabolically

320 healthy condition, which may be taken into account in the future studies.

321 Our study is the first review and meta-analysis to indicate the elevated risk of CAC in MHO

322 compared with MHNO subjects. However, some limitations should be taken into account. First,

323 only six studies were included in the meta-analysis and nine studies in our review, of which six

324 were conducted in Korea (Chang et al. 2014; Jung et al. 2014; Kang et al. 2017; Rhee et al. 2013;

325 Sung et al. 2014; Yoon et al. 2017) while the other three were from the USA and Germany.

326 (Echouffo-Tcheugui et al. 2019; Khan et al. 2011; Kowall et al. 2019) Another issue is that the

327 sample size varied substantially, mainly among cross-sectional studies. Although they all scored 
328 highly on the NOS scale, more studies are needed from other countries to confirm our results.

329 Second, the included studies differed in their definitions of metabolically healthy and obese.

330 Although we performed subgroup analyses in which MHO defined by NCEP ATP-III with $I^{2}$

$331=0 \%$ showed elevated risk of CAC compared with MHNO, more studies are needed in which

332 metabolically healthy is defined by JIS or using a universally accepted definition. In other words,

333 most of our included studies use BMI alone to define obesity,(Chang et al. 2014; Echouffo-

334 Tcheugui et al. 2019; Jung et al. 2014; Kang et al. 2017; Khan et al. 2011; Kowall et al. 2019;

335 Yoon et al. 2017) which may not be sufficient to distinguish between fat and lean tissue.

336 Adiposity measures between Asian and Caucasian populations cannot be easily compared, and

337 BMI cut-offs separating normal weight, overweight and obesity differ between these

338 populations, this limitation may have affected the results. A recent study suggested that using

339 BMI alone is not appropriate. (Chrysant \& Chrysant 2019) Thus further studies using or combing

340 other indices are warranted. Third, three of the studies included in our meta-analysis were cross-

341 sectional, precluding establishment of a temporal relationship. We performed a subgroup

342 analysis by study design and synthesis of cohort studies that showed significantly higher odds of

$343 \mathrm{CAC}$ progression in MHO. Fourth, with regards to statistical limitations, the recommended

344 minimum number of studies suggested in order to conduct a meta-regression is ten.(JP et al.

345 2011) Although age and smoking were possible important effect modifiers of the association 
346 between $\mathrm{MHO}$ and CAC risk, there are only five studies included in the meta-regression.

347 Therefore, we need more research to confirm the results.

348 CAC is an early indicator of atherosclerotic disease and a more accurate predictor of CVD

349 than traditional risk factors. Another commonly used subclinical measure of CVD is common

350 carotid intima medial thickness (CCA-IMT), an indicator of arterial wall thickness and

351 atherosclerotic disease progression. Bobbioni-Harsch et al. performed a three-year progression

352 evaluation showing significantly elevated CCA-IMT in MHO compared to normal body weight

353 (Bobbioni-Harsch et al. 2012) which is consistent with our results.

354 


\section{Conclusions}

356 Our study showed a significant association between MHO and elevated risk of CAC, which

357 in turn reflects the extent of coronary atherosclerosis. People with obesity should strive to

358 achieve normal weight even when only one metabolic abnormality is present.

359

360 Acknowledgements

361 Thanks to the MacKay Memorial Hospital librarian, Pei-jin Li, for examining the

362 references. We would like to thank Anthony Abram (www.uni-edit.net) for editing and

363 proofreading this manuscript. We thank to the Wei-hsin Liang, physician of MacKay Memorial

364 Hospital, for reviewing this manuscript. 


\section{Reference}

366 Alberti KG, Eckel RH, Grundy SM, Zimmet PZ, Cleeman JI, Donato KA, Fruchart JC, James WP,

367 Loria CM, Smith SC, Jr., International Diabetes Federation Task Force on E, Prevention, Hational

368 Heart L, Blood I, American Heart A, World Heart F, International Atherosclerosis S, and

369 International Association for the Study of O. 2009. Harmonizing the metabolic syndrome: a joint

370 interim statement of the International Diabetes Federation Task Force on Epidemiology and

371 Prevention; National Heart, Lung, and Blood Institute; American Heart Association; World Heart

372 Federation; International Atherosclerosis Society; and International Association for the Study of

373 Obesity. Circulation 120:1640-1645. 10.1161/CIRCULATIONAHA.109.192644

374 Amrhein V, Greenland S, and McShane B. 2019. Scientists rise up against statistical significance.

375 Nature Publishing Group.

376 Amrhein $V$, Korner-Nievergelt $F$, and Roth T. 2017. The earth is flat $(p>0.05)$ : significance

377 thresholds and the crisis of unreplicable research. PeerJ 5:e3544. 10.7717/peerj.3544

378 Appleton SL, Seaborn CJ, Visvanathan R, Hill CL, Gill TK, Taylor AW, Adams RJ, and North West

379 Adelaide Health Study T. 2013. Diabetes and cardiovascular disease outcomes in the

380 metabolically healthy obese phenotype: a cohort study. Diabetes Care 36:2388-2394.

$381 \quad 10.2337 / \mathrm{dc} 12-1971$ 
382 Bastien M, Poirier P, Lemieux I, and Despres JP. 2014. Overview of epidemiology and

383 contribution of obesity to cardiovascular disease. Prog Cardiovasc Dis 56:369-381.

384 10.1016/j.pcad.2013.10.016

385 Bluher M. 2010. The distinction of metabolically 'healthy' from 'unhealthy' obese individuals.

386 Curr Opin Lipidol 21:38-43. 10.1097/MOL.0b013e3283346ccc

387 Bobbioni-Harsch E, Pataky Z, Makoundou V, Laville M, Disse E, Anderwald C, Konrad T, Golay A,

388 and Investigators R. 2012. From metabolic normality to cardiometabolic risk factors in subjects

389 with obesity. Obesity (Silver Spring) 20:2063-2069. 10.1038/oby.2012.69

390 Budoff MJ, Achenbach S, Blumenthal RS, Carr JJ, Goldin JG, Greenland P, Guerci AD, Lima JA,

391 Rader DJ, Rubin GD, Shaw L, and Wiegers SE. 2006. Assessment of coronary artery disease by

392 cardiac computed tomography: a scientific statement from the American Heart Association

393 Committee on Cardiovascular Imaging and Intervention, Council on Cardiovascular Radiology

394 and Intervention, and Committee on Cardiac Imaging, Council on Clinical Cardiology. Circulation

395 114:1761-1791. 10.1161/circulationaha.106.178458

396 Chang Y, Kim BK, Yun KE, Cho J, Zhang Y, Rampal S, Zhao D, Jung HS, Choi Y, Ahn J, Lima JA, Shin

397 H, Guallar E, and Ryu S. 2014. Metabolically-healthy obesity and coronary artery calcification. J

398 Am Coll Cardiol 63:2679-2686. 10.1016/j.jacc.2014.03.042 
399 Chrysant SG, and Chrysant GS. 2019. The single use of body mass index for the obesity paradox

400 is misleading and should be used in conjunction with other obesity indices. Postgrad Med

401 131:96-102. 10.1080/00325481.2019.1568019

402 Collaboration NCDRF. 2016. Trends in adult body-mass index in 200 countries from 1975 to

403 2014: a pooled analysis of 1698 population-based measurement studies with 19.2 million

404 participants. Lancet 387:1377-1396. 10.1016/S0140-6736(16)30054-X

405 DerSimonian R, and Laird N. 1986. Meta-analysis in clinical trials. Control Clin Trials 7:177-188.

406 Echouffo-Tcheugui JB, Short MI, Xanthakis V, Field P, Sponholtz TR, Larson MG, and Vasan RS.

407 2019. Natural History of Obesity Subphenotypes: Dynamic Changes Over Two Decades and

408 Prognosis in the Framingham Heart Study. Journal of Clinical Endocrinology and Metabolism

409 104:738-752. 10.1210/jc.2018-01321

410 Eckel N, Meidtner K, Kalle-UhImann T, Stefan N, and Schulze MB. 2016. Metabolically healthy

411 obesity and cardiovascular events: A systematic review and meta-analysis. Eur J Prev Cardiol

$412 \quad 23: 956-966.10 .1177 / 2047487315623884$

413 Egger M, Davey Smith G, Schneider M, and Minder C. 1997. Bias in meta-analysis detected by a

414 simple, graphical test. Bmj 315:629-634. 10.1136/bmj.315.7109.629 
415 Estruch R, Ros E, Salas-Salvado J, Covas MI, Corella D, Aros F, Gomez-Gracia E, Ruiz-Gutierrez V,

416 Fiol M, Lapetra J, Lamuela-Raventos RM, Serra-Majem L, Pinto X, Basora J, Munoz MA, Sorli JV,

417 Martinez JA, and Martinez-Gonzalez MA. 2013. Primary prevention of cardiovascular disease

418 with a Mediterranean diet. New England Journal of Medicine 368:1279-1290.

Expert Panel on Detection E, and Treatment of High Blood Cholesterol in A. 2001. Executive

421 Summary of The Third Report of The National Cholesterol Education Program (NCEP) Expert

422 Panel on Detection, Evaluation, And Treatment of High Blood Cholesterol In Adults (Adult

423 Treatment Panel III). Jama 285:2486-2497. 10.1001/jama.285.19.2486

424 Fan J, Song Y, Chen Y, Hui R, and Zhang W. 2013. Combined effect of obesity and cardio-

425 metabolic abnormality on the risk of cardiovascular disease: a meta-analysis of prospective

426 cohort studies. Int J Cardiol 168:4761-4768. 10.1016/j.ijcard.2013.07.230

427 Hamer M, and Stamatakis E. 2012. Metabolically healthy obesity and risk of all-cause and

428 cardiovascular disease mortality. J Clin Endocrinol Metab 97:2482-2488. 10.1210/jc.2011-3475

429 Higgins JP, and Thompson SG. 2002. Quantifying heterogeneity in a meta-analysis. Stat Med

$430 \quad 21: 1539-1558.10 .1002 / \operatorname{sim} .1186$

431 Hosseinpanah F, Barzin M, Sheikholeslami F, and Azizi F. 2011. Effect of different obesity 
432 phenotypes on cardiovascular events in Tehran Lipid and Glucose Study (TLGS). Am J Cardiol

433 107:412-416. 10.1016/j.amjcard.2010.09.034

434 Jeppesen J, Hansen TW, Olsen MH, Rasmussen S, Ibsen H, Torp-Pedersen C, Hildebrandt PR, and

435 Madsbad S. 2008. C-reactive protein, insulin resistance and risk of cardiovascular disease: a

436 population-based study. Eur J Cardiovasc Prev Rehabil 15:594-598.

437 10.1097/HJR.0b013e328308bb8b

438 JP H, S G, and editor(s). 2011. Cochrane Handbook for Systematic Reviews of Interventions

439 Version 5.1 .0 (updated March 2011). The Cochrane Collaboration, 2011. Available at

440 https://handbook-5-1.cochrane.org/chapter_9/9_6_4_meta_regression.htm.

441 Jung CH, Lee MJ, Hwang JY, Jang JE, Leem J, Yang DH, Kang JW, Kim EH, Park JY, Kim HK, and Lee

442 WJ. 2014. Association of metabolically healthy obesity with subclinical coronary atherosclerosis

443 in a Korean population. Obesity (Silver Spring) 22:2613-2620. 10.1002/oby.20883

444 Kang YM, Jung CH, Cho YK, Lee SE, Lee MJ, Hwang JY, Kim EH, Park JY, Lee WJ, and Kim HK.

445 2017. Fatty liver disease determines the progression of coronary artery calcification in a

446 metabolically healthy obese population. PLoS One 12:e0175762.

447 10.1371/journal.pone.0175762

448 Kantartzis K, Machann J, Schick F, Rittig K, Machicao F, Fritsche A, Haring HU, and Stefan N. 
449 2011. Effects of a lifestyle intervention in metabolically benign and malign obesity. Diabetologia

$450 \quad$ 54:864-868. 10.1007/s00125-010-2006-3

451 Khan UI, Wang D, Thurston RC, Sowers M, Sutton-Tyrrell K, Matthews KA, Barinas-Mitchell E,

452 and Wildman RP. 2011. Burden of subclinical cardiovascular disease in "metabolically benign"

453 and "at-risk" overweight and obese women: the Study of Women's Health Across the Nation

454 (SWAN). Atherosclerosis 217:179-186. 10.1016/j.atherosclerosis.2011.01.007

455 Kowall B, Lehmann N, Mahabadi AA, Moebus S, Erbel R, Jockel KH, and Stang A. 2019.

456 Associations of metabolically healthy obesity with prevalence and progression of coronary

457 artery calcification: Results from the Heinz Nixdorf Recall Cohort Study. Nutr Metab Cardiovasc

458 Dis 29:228-235. 10.1016/j.numecd.2018.11.002

459 Kramer CK, Zinman B, and Retnakaran R. 2013. Are metabolically healthy overweight and

460 obesity benign conditions?: A systematic review and meta-analysis. Ann Intern Med 159:758-

461 769. 10.7326/0003-4819-159-11-201312030-00008

462 Kumagai S, Amano T, Takashima H, Waseda K, Kurita A, Ando H, Maeda K, Ito Y, Ishii H, Hayashi

463 M, Yoshikawa D, Suzuki S, Tanaka A, Matsubara T, and Murohara T. 2015. Impact of cigarette

464 smoking on coronary plaque composition. Coron Artery Dis 26:60-65. 
466 Lassale C, Tzoulaki I, Moons KGM, Sweeting M, Boer J, Johnson L, Huerta JM, Agnoli C, Freisling

$467 \mathrm{H}$, Weiderpass E, Wennberg P, van der A DL, Arriola L, Benetou V, Boeing H, Bonnet F, Colorado-

468 Yohar SM, Engström G, Eriksen AK, Ferrari P, Grioni S, Johansson M, Kaaks R, Katsoulis M,

469 Katzke V, Key TJ, Matullo G, Melander O, Molina-Portillo E, Moreno-Iribas C, Norberg M,

470 Overvad K, Panico S, Quirós JR, Saieva C, Skeie G, Steffen A, Stepien M, Tjønneland A,

471 Trichopoulou A, Tumino R, van der Schouw YT, Verschuren WMM, Langenberg C, Di

472 Angelantonio E, Riboli E, Wareham NJ, Danesh J, and Butterworth AS. 2017. Separate and

473 combined associations of obesity and metabolic health with coronary heart disease: a pan-

474 European case-cohort analysis. European Heart Journal 39:397-406. 10.1093/eurheartj/ehx448

475 Lehmann N, Mohlenkamp S, Mahabadi AA, Schmermund A, Roggenbuck U, Seibel R,

476 Gronemeyer D, Budde T, Dragano N, Stang A, Mann K, Moebus S, Erbel R, and Jockel KH. 2014.

477 Effect of smoking and other traditional risk factors on the onset of coronary artery calcification:

478 results of the Heinz Nixdorf recall study. Atherosclerosis 232:339-345.

479 10.1016/j.atherosclerosis.2013.11.045

480 Loria CM, Liu K, Lewis CE, Hulley SB, Sidney S, Schreiner PJ, Williams OD, Bild DE, and Detrano R.

481 2007. Early adult risk factor levels and subsequent coronary artery calcification: the CARDIA

482 Study. J Am Coll Cardiol 49:2013-2020. 10.1016/j.jacc.2007.03.009 
483 Maher JE, Bielak LF, Raz JA, Sheedy PF, 2nd, Schwartz RS, and Peyser PA. 1999. Progression of

484 coronary artery calcification: a pilot study. Mayo Clin Proc 74:347-355. 10.4065/74.4.347

485 Mirzababaei A, Djafarian K, Mozafari H, and Shab-Bidar S. 2019. The long-term prognosis of

486 heart diseases for different metabolic phenotypes: a systematic review and meta-analysis of

487 prospective cohort studies. Endocrine 63:439-462. 10.1007/s12020-019-01840-0

488 Mongraw-Chaffin M, Foster MC, Kalyani RR, Vaidya D, Burke GL, Woodward M, and Anderson

489 CA. 2016. Obesity Severity and Duration Are Associated With Incident Metabolic Syndrome:

490 Evidence Against Metabolically Healthy Obesity From the Multi-Ethnic Study of Atherosclerosis.

491 Journal of Clinical Endocrinology and Metabolism 101:4117-4124. 10.1210/jc.2016-2460

492 Mottillo S, Filion KB, Genest J, Joseph L, Pilote L, Poirier P, Rinfret S, Schiffrin EL, and Eisenberg

493 MJ. 2010. The metabolic syndrome and cardiovascular risk a systematic review and meta-

494 analysis. J Am Coll Cardiol 56:1113-1132. 10.1016/j.jacc.2010.05.034

495 Otsuka F, Sakakura K, Yahagi K, Joner M, and Virmani R. 2014. Has our understanding of

496 calcification in human coronary atherosclerosis progressed? Arterioscler Thromb Vasc Biol

497 34:724-736. 10.1161/ATVBAHA.113.302642

498 Rasaei N, Mirzababaei A, Arghavani H, Tajik S, Keshavarz SA, Yekaninejad MS, Imani H, and

499 Mirzaei K. 2018. A comparison of the sensitivity and specificity of anthropometric

Peer] reviewing PDF | (2019:09:41480:3:1:NEW 20 Feb 2020) 
500 measurements to predict unhealthy metabolic phenotype in overweight and obese women.

501 Diabetes Metab Syndr 12:1147-1153. 10.1016/j.dsx.2018.06.023

502 Rhee EJ, Seo MH, Kim JD, Jeon WS, Park SE, Park CY, Oh KW, Park SW, and Lee WY. 2013.

503 Metabolic health is more closely associated with coronary artery calcification than obesity. PLoS

504 One 8:e74564. 10.1371/journal.pone.0074564

505 Roberson LL, Aneni EC, Maziak W, Agatston A, Feldman T, Rouseff M, Tran T, Blaha MJ, Santos

506 RD, Sposito A, Al-Mallah MH, Blankstein R, Budoff MJ, and Nasir K. 2014. Beyond BMI: The

507 "Metabolically healthy obese" phenotype \& its association with clinical/subclinical

508 cardiovascular disease and all-cause mortality -- a systematic review. BMC public health 14:14.

509 10.1186/1471-2458-14-14

510 Roca-Rivada A, Bravo SB, Perez-Sotelo D, Alonso J, Castro Al, Baamonde I, Baltar J, Casanueva

511 FF, and Pardo M. 2015. CILAIR-Based Secretome Analysis of Obese Visceral and Subcutaneous

512 Adipose Tissues Reveals Distinctive ECM Remodeling and Inflammation Mediators. Sci Rep

513 5:12214. 10.1038/srep12214

514 Ronti T, Lupattelli G, and Mannarino E. 2006. The endocrine function of adipose tissue: an

515 update. Clin Endocrinol (Oxf) 64:355-365. 10.1111/j.1365-2265.2006.02474.x

516 Rothman KJ. 2012. Epidemiology: an introduction: Oxford university press. 
517 Seidell JC, and Halberstadt J. 2015. The global burden of obesity and the challenges of

518 prevention. Ann Nutr Metab 66 Suppl 2:7-12. 10.1159/000375143

519 Shamseer L, Moher D, Clarke M, Ghersi D, Liberati A, Petticrew M, Shekelle P, Stewart LA, and

520 Group P-P. 2015. Preferred reporting items for systematic review and meta-analysis protocols

521 (PRISMA-P) 2015: elaboration and explanation. BMJ 350:g7647. 10.1136/bmj.g7647

522 Stefan N, Haring HU, Hu FB, and Schulze MB. 2013. Metabolically healthy obesity:

523 epidemiology, mechanisms, and clinical implications. Lancet Diabetes Endocrinol 1:152-162.

524 10.1016/s2213-8587(13)70062-7

525 Stefan N, Haring HU, and Schulze MB. 2018. Metabolically healthy obesity: the low-hanging

526 fruit in obesity treatment? Lancet Diabetes Endocrinol 6:249-258. 10.1016/s2213-

$5278587(17) 30292-9$

528 Stefan N, Schick F, and Haring HU. 2017. Causes, Characteristics, and Consequences of

529 Metabolically Unhealthy Normal Weight in Humans. Cell Metabolism 26:292-300.

530 10.1016/j.cmet.2017.07.008

531 Sung KC, Cha SC, Sung JW, So MS, and Byrne CD. 2014. Metabolically healthy obese subjects are

532 at risk of fatty liver but not of pre-clinical atherosclerosis. Nutr Metab Cardiovasc Dis 24:256-

533 262. 10.1016/j.numecd.2013.07.005 
534 Team RC. 2013. R: A language and environment for statistical computing. 1.1.456 ed.

535 Velho S, Paccaud F, Waeber G, Vollenweider P, and Marques-Vidal P. 2010. Metabolically

536 healthy obesity: different prevalences using different criteria. Eur J Clin Nutr 64:1043-1051.

537 10.1038/ejcn.2010.114

538 Wildman RP, Muntner P, Reynolds K, McGinn AP, Rajpathak S, Wylie-Rosett J, and Sowers MR.

539 2008. The obese without cardiometabolic risk factor clustering and the normal weight with

540 cardiometabolic risk factor clustering: prevalence and correlates of 2 phenotypes among the US

541 population (NHANES 1999-2004). Arch Intern Med 168:1617-1624.

542 10.1001/archinte.168.15.1617

543 Yoon JW, Jung CH, Kim MK, Park HE, Park KS, Jang HC, Moon MK, Choi SY, and Koo BK. 2017.

544 Influence of the definition of "metabolically healthy obesity" on the progression of coronary

545 artery calcification. PLoS One 12:e0178741. 10.1371/journal.pone.0178741

546 Zeng X, Zhang Y, Kwong JS, Zhang C, Li S, Sun F, Niu Y, and Du L. 2015. The methodological

547 quality assessment tools for preclinical and clinical studies, systematic review and meta-

548 analysis, and clinical practice guideline: a systematic review. Journal of Evidence-Based

549 Medicine 8:2-10. 10.1111/jebm.12141

550 Zheng R, Zhou D, and Zhu Y. 2016. The long-term prognosis of cardiovascular disease and all- 
551 cause mortality for metabolically healthy obesity: a systematic review and meta-analysis. J

552 Epidemiol Community Health 70:1024-1031. 10.1136/jech-2015-206948

553

554 


\section{Table 1 (on next page)}

Characteristics of included studies 
Table 1: Characteristics of included studies

\begin{tabular}{|c|c|c|c|c|c|c|}
\hline Study & Participants & $\begin{array}{l}\text { Obesity } \\
\text { definition: } \\
\text { BMI }\left(\mathrm{kg} / \mathrm{m}^{2}\right) \\
\text { or } \mathrm{WC}(\mathrm{cm})\end{array}$ & $\begin{array}{l}\text { Definition of } \\
\text { metabolic healthy } \\
\text { (criteria and } \\
\text { numbers of } \\
\text { components }\end{array}$ & $\begin{array}{l}\text { Adjusted } \\
\text { variables }\end{array}$ & $\begin{array}{l}\text { Diagnostic criteria and main } \\
\text { results presented by MHO } \\
\text { compared with MHNO with } \\
\text { OR }(95 \% \mathrm{CI})\end{array}$ & NOS \\
\hline $\begin{array}{l}\text { Khan, } 2011 \\
\text { (Khan et al. } \\
\text { 2011) }\end{array}$ & $\begin{array}{l}\text { USA, Study of } \\
\text { Women's Health } \\
\text { Across the } \\
\text { Nation, N=475, } \\
100 \% \text { women, } \\
55 \% \text { in MHO, } \\
50.9 \text { y/o, cross } \\
\text { sectional }\end{array}$ & $\begin{array}{l}\text { BMI } \geq 25 \\
\text { (include } \\
\text { overweight } \\
\text { and obese) }\end{array}$ & $\begin{array}{l}\text { NCEP-ATP III } \\
(\text { except WC) +CRP } \\
\geq 3.0 \mathrm{mg} / \mathrm{dL} \\
\text { MHO: }<3\end{array}$ & $\begin{array}{l}\text { age, site of } \\
\text { recruitment, } \\
\text { education, } \\
\text { race, smoking }\end{array}$ & $\begin{array}{l}\text { CACS } \geq 10 \text { assessed by CT } \\
\text { MHO/MHOW vs MHNW: } \\
\text { OR 2.38(1.2-4.7) }\end{array}$ & 9 \\
\hline $\begin{array}{l}\text { Rhee, } 2013 \\
\text { (Rhee et al. } \\
\text { 2013) }\end{array}$ & $\begin{array}{l}\text { Korea, part of } \\
\text { Kangbuk } \\
\text { Samsung Health } \\
\text { Study } \\
\mathrm{N}=24063,82 \% \\
\text { women, } 18.2 \% \\
\text { in MHO, } 41.3 \\
\text { y/o, cross } \\
\text { sectional }\end{array}$ & $\begin{array}{l}\mathrm{BMI} \geq 25 \\
\text { or } \\
\mathrm{WC} \mathrm{(} \geq 90 \text { in } \\
\text { men, } \geq 80 \text { in } \\
\text { women })\end{array}$ & $\begin{array}{l}\text { Wildman criteria } \\
\text { MHO: } \leq 2\end{array}$ & $\begin{array}{l}\text { age, sex, } \\
\text { smoking, SBP, } \\
\text { FBS, TC, TG, } \\
\text { hs-CRP, Ca }\end{array}$ & $\begin{array}{l}\text { CACS assessed by CT: } \\
\text { OR for different CACS } \\
\text { categories } \\
\text { CAC 1-10: } 1.23(1.03-1.48) \\
\quad 11-100: 1.16(0.97-1.38) \\
\quad 101-400: 1.43(1.00- \\
2.06) \\
\quad>400: 1.79(0.84-3.79)\end{array}$ & 7 \\
\hline
\end{tabular}




\begin{tabular}{|c|c|c|c|c|c|c|}
\hline $\begin{array}{l}\text { Sung, } 2014 \\
\text { (Sung et al. } \\
2014 \text { ) }\end{array}$ & $\begin{array}{l}\text { Korea, Kangbuk } \\
\text { Samsung } \\
\text { Hospital } \\
\mathrm{N}=14384,17.5 \% \\
\text { women, } 6.6 \% \text { in } \\
\text { MHO, } 41.3 \text { y/o, } \\
\text { cross sectional }\end{array}$ & $\begin{array}{l}\mathrm{BMI} \geq 25 \\
\text { or } \\
\mathrm{WC}(\geq 90 \text { in } \\
\text { men, } \geq 80 \text { in } \\
\text { women) }\end{array}$ & $\begin{array}{l}\text { JIS criteria } \\
\text { MHO: }=0\end{array}$ & $\begin{array}{l}\text { Age, sex, } \\
\text { smoking, } \\
\text { alcohol, } \\
\text { exercise, LDL- } \\
\text { C, HOMA-IR, } \\
\text { CRP, TSH }\end{array}$ & $\begin{array}{l}\text { CACS assessed by CT } \\
(\mathrm{CACS}>0) \\
\text { MHO: OR } 0.93(0.67-1.31)\end{array}$ & 8 \\
\hline $\begin{array}{l}\text { Chang, } 2014 \\
\text { (Chang et al. } \\
\text { 2014) }\end{array}$ & $\begin{array}{l}\text { Korea, part of } \\
\text { Kangbuk } \\
\text { Samsung Health } \\
\text { Study, N=14828, } \\
25.8 \% \text { women, } \\
21.9 \% \text { in MHO, } \\
39.3 \text { y/o, cross } \\
\text { sectional }\end{array}$ & $\mathrm{BMI} \geq 25$ & $\begin{array}{l}\text { NCEP-ATP III } \\
\text { (except WC) and } \\
\text { HOMA-IR } \\
\text { MHO: }=0 \text { and } \\
\text { HOMA-IR }<2.5\end{array}$ & $\begin{array}{l}\text { age, sex, } \\
\text { smoking, } \\
\text { alcohol, } \\
\text { exercise, } \\
\text { education }\end{array}$ & $\begin{array}{l}\text { CACS assessed by CT } \\
\text { MHO vs MHNW: } \\
\text { a. CACS ratio: } 2.26 \text { (1.48- } \\
\text { 3.43) } \\
\text { b. prevalence ratio of } \\
\text { 1.CACS }>80: 1.67(1.09- \\
\text { 2.56) } \\
\text { 2.CACS1-80: } 1.39(1.15- \\
\text { 1.67) }\end{array}$ & 7 \\
\hline $\begin{array}{l}\text { Jung, } \\
2014 \text { (Jung et al. } \\
2014 \text { ) }\end{array}$ & $\begin{array}{l}\text { Korea, Asan } \\
\text { Medical Center, } \\
\mathrm{N}=4009,17.7 \% \\
\text { women, } 14.7 \% \\
\text { in MHO, } 52.3 \\
\text { y/o, cross } \\
\text { sectional }\end{array}$ & $\mathrm{BMI} \geq 25$ & $\begin{array}{l}\text { Wildman criteria } \\
\text { MHO: } \leq 1\end{array}$ & $\begin{array}{l}\text { age, sex, WC, } \\
\text { alcohol, } \\
\text { smoking, } \\
\text { exercise, } \\
\text { diabetes, SBP, } \\
\text { FBS, ALT, } \\
\text { GGT, uric acid, } \\
\text { LDL-C, HDL- }\end{array}$ & $\begin{array}{l}\text { CACS assessed by CT } \\
\text { CACS >0: } 1.38(1.04-1.82) \\
0.1-100: 1.32(0.98- \\
1.79) \\
\quad>100: 1.69(1.03- \\
2.78)\end{array}$ & 8 \\
\hline
\end{tabular}




\begin{tabular}{|c|c|c|c|c|c|c|}
\hline & & & & $\begin{array}{l}\text { C, hs-CRP, } \\
\text { HOMA-IR. }\end{array}$ & & \\
\hline $\begin{array}{l}\text { Yoon,2017(Yoon } \\
\text { et al. 2017) }\end{array}$ & $\begin{array}{l}\text { Korea, Seoul } \\
\text { National } \\
\text { University } \\
\text { Hospital, } \\
\mathrm{N}=1218,27.6 \% \\
\text { women, } 15.6 \% \\
\text { in MHO I, } 54.6 \\
\text { y/o, } 3.75 \text { yrs f/u }\end{array}$ & $\mathrm{BMI} \geq 25$ & $\begin{array}{l}\text { NCEP-ATP III } \\
(\text { except WC) } \\
\text { MHO I }: \leq 1 \\
\text { MHO II }:=0\end{array}$ & age, sex & $\begin{array}{l}\text { CACS progression (any } \\
\text { Agatston score increase }>0 \\
\text { at f/u) by CT } \\
\text { MHO I: OR: } 1.65(1.14- \\
2.40) \\
\text { MHO II: OR: } 1.20(0.51- \\
2.78)\end{array}$ & 8 \\
\hline $\begin{array}{l}\text { Kang, } 2017 \\
\text { (Kang et al. } \\
\text { 2017) }\end{array}$ & $\begin{array}{l}\text { Korea, Asan } \\
\text { Medical Center, } \\
\mathrm{N}=1240,18.3 \% \\
\text { women, } 22.7 \% \\
\text { in MHO, } 54.2 \\
\text { y/o, } 2.9 \text { yrs f/u }\end{array}$ & $\mathrm{BMI} \geq 25$ & $\begin{array}{l}\text { NCEP-ATP III } \\
\text { (except WC) } \\
\text { MHO: } \leq 1\end{array}$ & $\begin{array}{l}\text { age, sex, WC, } \\
\text { alcohol, } \\
\text { smoking, } \\
\text { exercise, } \\
\text { baseline CAC } \\
\text { score, LDL-C, } \\
\text { hs-CRP, and } \\
\text { f/u interval }\end{array}$ & $\begin{array}{l}\text { CACS progression (any } \geq 2.5 \\
\text { units } \\
\text { between the baseline and } \\
\text { final square root of the } \\
\text { CACS) by CT } \\
\text { MHO: OR } 1.45(0.93-2.25)\end{array}$ & 9 \\
\hline $\begin{array}{l}\text { Kowall, } 2018 \\
\text { (Kowall et al. } \\
2018 \text { ) }\end{array}$ & $\begin{array}{l}\text { Germany, Heinz } \\
\text { Nixdorf Recall } \\
\text { Study, N=1585, } \\
60.5 \% \text { women, } \\
10.0 \% \text { in } \mathrm{MHO},\end{array}$ & $\mathrm{BMI} \geq 30$ & $\begin{array}{l}\text { NCEP-ATP III } \\
\text { (except WC) } \\
\text { MHO I }: \leq 1 \\
\text { MHO II }:=0\end{array}$ & $\begin{array}{l}\text { age, sex, } \\
\text { smoking, } \\
\text { physical } \\
\text { activity, } \\
\text { education }\end{array}$ & $\begin{array}{l}\text { Categorical variable for } \\
\text { annual absolute CAC change } \\
\text { (CAC at f/u minus CAC at } \\
\text { baseline): } \geq 100 \mathrm{AU} ; 10-99 \\
\text { AU; }<10 \mathrm{AU}\end{array}$ & 9 \\
\hline
\end{tabular}




\begin{tabular}{|c|c|c|c|c|c|c|}
\hline & $\begin{array}{l}58.3 \text { y/o, } 5.1 \text { yrs } \\
\mathrm{f} / \mathrm{u}\end{array}$ & & & & $\begin{array}{l}\text { OR calculated from ordinal } \\
\text { logistic regression models } \\
\text { (vs MHNW) } \\
\text { MHO I: } 1.24(0.78-1.97) \\
\text { MHO II: } 1.29(0.43-3.9)\end{array}$ & \\
\hline $\begin{array}{l}\text { Echouffo- } \\
\text { Tcheugui, } 2019 \\
\text { (Echouffo- } \\
\text { Tcheugui et al. } \\
2019 \text { ) }\end{array}$ & $\begin{array}{l}\text { United States, } \\
\text { Framingham } \\
\text { Offspring Study, } \\
\mathrm{N}=1107, \mathrm{~N} / \mathrm{A} \% \\
\text { women, N/A \% } \\
\text { in MHO, } 45 \mathrm{y} / \mathrm{o}, \\
\text { cross sectional }\end{array}$ & $\mathrm{BMI} \geq 30$ & $\begin{array}{l}\text { NCEP-ATP III } \\
(\text { except WC) } \\
\text { MHO: } \leq 1\end{array}$ & $\begin{array}{l}\text { age, sex, } \\
\text { smoking }\end{array}$ & $\begin{array}{l}\text { CAC score }>100 \text {, assessed } \\
\text { by CT } \\
\text { MHO: OR } 1.94(1.18-3.19)\end{array}$ & 7 \\
\hline
\end{tabular}

ALT, alanine aminotransferase; AU, Agatston units; BMI, body mass index; BP, blood pressure; CAC, coronary artery calcification;

3 CACS, coronary artery calcification score; Ca, calcium; CI, confidence interval; cm, centimeter; CT, computed tomography; CRP, C reactive protein; FBS, fasting blood sugar; f/u, follow/up; GGT, gamma glutamyl transpeptidase; HDL-C, high-density lipoprotein Cholesterol; HOMA-IR, homeostatic model of the assessment of insulin resistance; hs-CRP, high-sensitivity C-reactive protein; JIS, Joint Interim Statement; LDL-C, Low Density Lipoprotein Cholesterol; MHO, metabolically health obesity; MHNO, metabolically

7 healthy non-obese; MHNW, metabolically healthy normal-weight; N/A, not available; NCEP-ATP III, National Cholesterol Education

8 Program-Adult Treatment Panel III; NOS, Newcastle-Ottawa Scale; OR, odd ratio; SBP, systolic blood pressure; TC, total cholesterol;

TG, triglyceride; TSH, Thyroid-stimulating hormone; WC, waist circumference; yrs, years 
Figure 1

Flowchart of the study selection process 


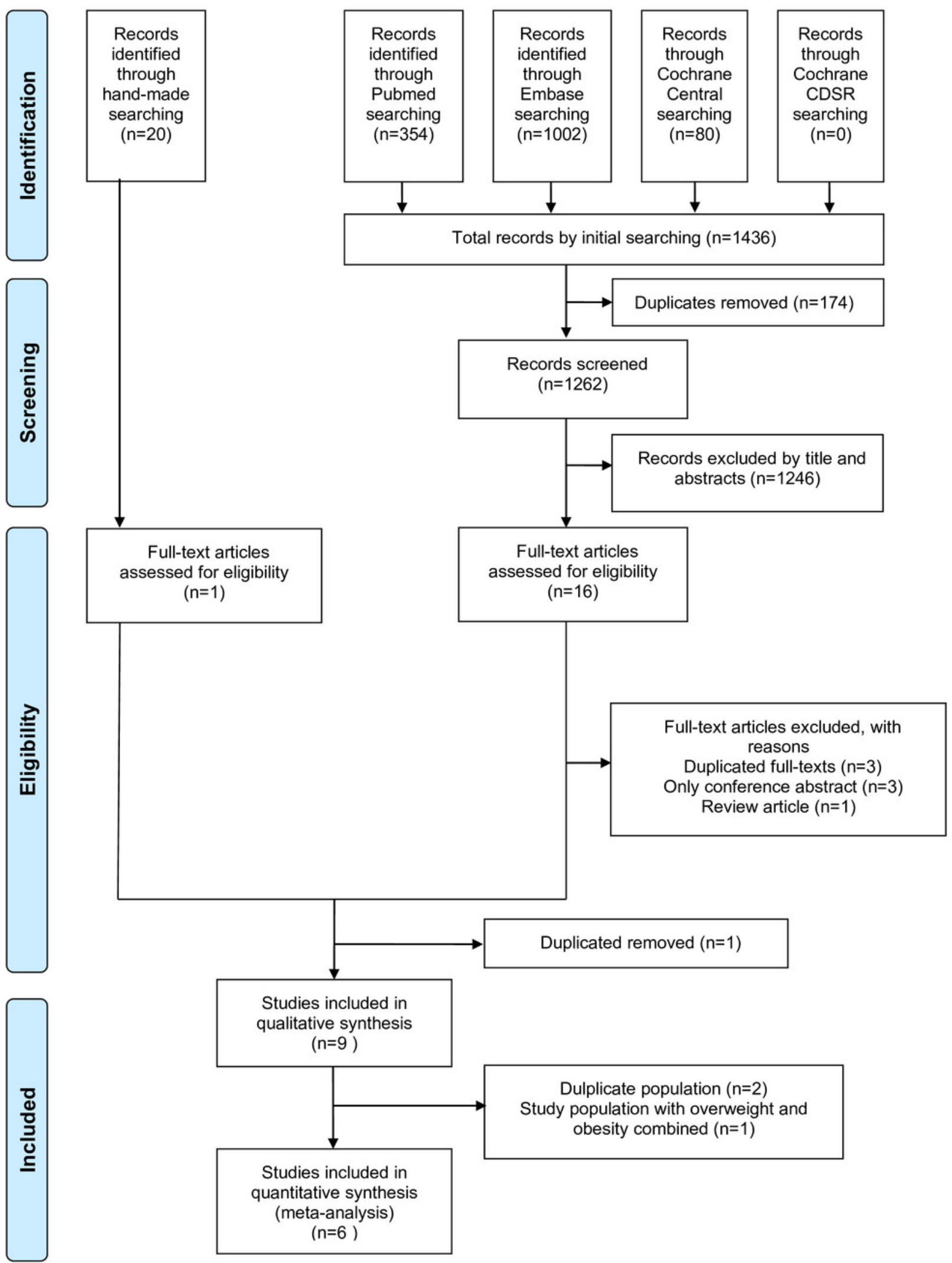


Figure 2

Forest plot of CAC risk, comparing participants with metabolically healthy obesity as those with metabolically healthy non-obesity, with subgroup analysis by article design

CAC, coronary artery calcification; $\mathrm{Cl}$, confidence interval; OR, odds ratio; SE, standard error; TE, treatment effect

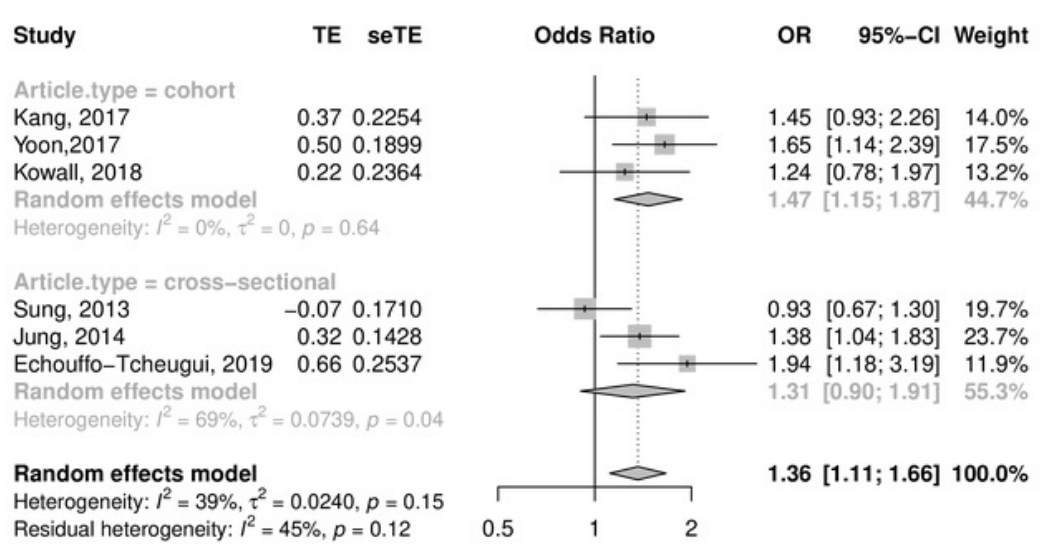


Figure 3

Forest plot of CAC risk, comparing participants with metabolically healthy obesity as those with metabolically healthy non-obesity, with subgroup analysis by definition of metabolic health

ATP III, Adult Treatment program III; CAC, coronary artery calcification; Cl, confidence interval; JIS, Joint Interim Statement; OR, odds ratio; SE, standard error; TE, treatment effect

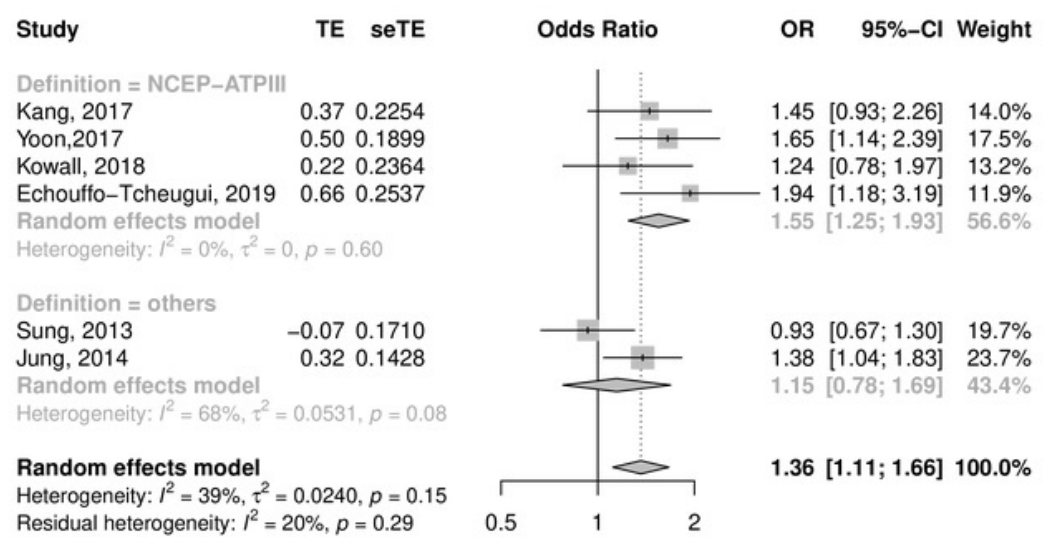

